\title{
Simulation of the Structure and Track of the Tropical Cyclone Sidr using Numerical Models
}

\author{
M. A. E. Akhter ${ }^{1,2 *}$, M. M. Alam ${ }^{1}$, M. A. K. Mallik ${ }^{3,4}$ \\ ${ }^{1}$ Department of Physics, Khulna University of Engineering \& Technology, Bangladesh \\ ${ }^{2}$ SAARC Meteorological Research Centre, Bangladesh \\ ${ }^{3}$ Bangladesh Meteorological Department, Bangladesh \\ ${ }^{4}$ Department of Physics, Jahangirnagar University, Savar, Dhaka Bangladesh
}

Received 3 October 2015, accepted in final revised form 22 March 2016

\begin{abstract}
Tropical cyclone (TC), one of the most devastating and deadly weather phenomena,is a result of organized intense convective activities over warm tropical oceans. In the recent years, mesoscale models are extensively used for simulation of genesis, intensification and movement of tropical cyclones. During 09-16 November, 2007, a severe cyclonic storm named, Sidr was active in the Bay of Bengal part of the Indian Ocean. At 16 UTC on 15 November 2007, the system crossed Bangladesh coast near at long. $89.8^{\circ} \mathrm{E}$. In the present study, two state-of-the-art mesoscale models, MM5 and WRF, have been used to simulate the structure and track of TC Sidr. Horizontal resolution of $90 \mathrm{~km}$ and $30 \mathrm{~km}$ respectively for mother and nested domain were used in both the models. Various meteorological fields' viz. central pressure, winds, vorticity, temperature anomaly etc. obtained from the simulations are verified against those observed to test their performance. The simulated tracks are also compared with those obtained from JTWC. The results indicate that MM5 model has better forecast skill in terms of intensity prediction but WRF model has better forecast skill in terms of track prediction of the cyclonic storm.
\end{abstract}

Keywords: Tropical cyclone; Mesoscale models; Intensity; Structure and track.

๑) 2016 JSR Publications. ISSN: 2070-0237 (Print); 2070-0245 (Online). All rights reserved. doi: http://dx.doi.org/10.3329/jsr.v8i2.25217

J. Sci. Res. 8 (2), 129-147 (2016)

\section{Introduction}

The Bay of Bengal tropical cyclone disaster is the deadliest natural hazard in the Indian sub-continent. It has a significant socio-economic impact on the countries bordering the Bay of Bengal, especially India, Bangladesh and Myanmar. Therefore, it is very important to predict these cyclones with high accuracy to save the valuable

\footnotetext{
* Corresponding author: afraabida@ hotmail.com
} 
lives and wealth. Recently, there have been considerable improvements in the field of weather prediction by numerical models. The Pennsylvania State University (PSU)/National Center for Atmospheric Research (NCAR) mesoscale model MM5 has been used in a number of studies for the simulation of tropical cyclones [1]. Mohanty et al. [2] used MM5 model to simulate the Orissa super cyclone (1999). Again, WRF model has also been used in a number of studies for the simulation of tropical cyclones $[3,4]$. There are a number of comparative studies on the performance of the mesoscale models for severe weather events triggered by convection. Sousounis et al. [5] made a comparative study on the performance of WRF, MM5, RUC and ETA models for heavy precipitation event and suggested that WRF model has the capability to generate physically realistic fine-scale structure which is not seen in the standard output resolution of other operational forecast models. Forecast skill of WRF model has been found better in the comparative study between WRF and ETA on the surface sensible weather forecast over Western United States [6]. On the other hand, better forecast skill of MM5 model has been demonstrated in the comparative study on the performance of MM5 and RAMS models in simulating the Bay of Bengal cyclone [7]. Again, Pattanayak et al. [8] made a comparative study on the performance of MM5 and WRF models in simulating tropical cyclones over Indian seas. The intensity of the tropical cyclones Mala, Gunu and Sidr in terms of MSLP and maximum sustainable wind illustrates that MM5 simulates the intensity of the system fairly, whereas WRF gives reasonably good results, similar to the observations. Rayhun et al. simulated the structure, track and landfall of tropical cyclone Bijli using WRF-ARW model [9]. One of the important findings of the study is that the model has successfully predicted the tracks, recurvature and probable areas and time of landfall of the selected tropical cyclone Bijli with high accuracy even in the $72 \mathrm{~h}$ predictions.

In the present study, MM5 version 3.7 and WRF-ARW version 3.1 are used to simulate the TC Sidr formed over Bay of Bengal. The performances of the models have been evaluated and compared with observations and verifying analyses.

\section{Model Description and Methodology}

MM5 has been widely used for simulation/prediction of severe weather events such as tropical cyclones, heavy rainfall, thunderstorms etc. MM5 is a nonhydrostatic mesoscale model with pressure perturbation $p^{\prime}$, three velocity components $(u, v, w)$, temperature $T$ and specific humidity $q$ as the prognostic variables. Model equations in the terrain following sigma co-ordinate are used in surface flux form and solved on Arakawa B grid. Leapfrog time integration scheme with time splitting technique is used in model integration. With a number of sensitivity tests, it has demonstrated that the combination of Kain-Fritisch cumulus parameterization scheme with MRF PBL, in general, provides better result for simulation of tropical cyclones [10]. Table 1 summarizes the model configuration and various options used by MM5 in the present study. 
The WRF-ARW modeling system developed by the Mesoscale and Microscale Meteorology (MMM) Division of NCAR is designed to be a flexible, state-of-the-art atmospheric simulation system which is suitable for a broad range of applications such as idealized simulations, parameterization research, data assimilation research, realtime NWP etc. Model equations are in the mass-based terrain following coordinate system and solved on Arakawa-C grid. Runge-Kutta 2nd and 3rd order time integration technique is used for model integration. The new generation of the MRF PBL scheme is introduced here as Yonsei University (YSU) PBL. It has an explicit representation of entrainment at the PBL top, which is derived from large eddy simulation [11]. Table 1 summarizes the model configuration and various options used by WRF-ARW in the present study are partly chosen from the study carried out by Pattanayak et al. [8].

Table 1. Brief description of the MM5 and WRF models.

\begin{tabular}{|c|c|c|}
\hline Parameters & Used for MM5 V 3.7 model & Used for WRF version 3.1 model \\
\hline Dynamics & $\begin{array}{l}\text { Non-hydrostatic with 3-D Coriolis } \\
\text { force }\end{array}$ & $\begin{array}{l}\text { Non-hydrostatic with 3-D Coriolis } \\
\text { force }\end{array}$ \\
\hline Mother Domain & $\begin{array}{l}0.22{ }^{\circ} \mathrm{S}-37.94{ }^{\circ} \mathrm{N}, 67.36^{\circ} \mathrm{E}-108.64 \\
{ }^{\circ} \mathrm{E}\end{array}$ & $\begin{array}{l}1.58{ }^{\circ} \mathrm{S}-38.94{ }^{\circ} \mathrm{N}, 66.10^{\circ} \mathrm{E}-110.02 \\
{ }^{\circ} \mathrm{E}\end{array}$ \\
\hline Inner Domain & $\begin{array}{l}5.36^{\circ} \mathrm{N}-28.71^{\circ} \mathrm{N}, 81.66^{\circ} \mathrm{E}-99.20 \\
{ }^{\circ} \mathrm{E}\end{array}$ & 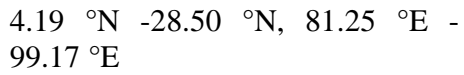 \\
\hline Resolution & 90 and $30 \mathrm{~km}$ & 90 and $30 \mathrm{~km}$ \\
\hline Map projection & Mercator & Mercator \\
\hline $\begin{array}{l}\text { No of vertical } \\
\text { levels }\end{array}$ & 28 & 28 \\
\hline $\begin{array}{l}\text { Horizontal grid } \\
\text { scheme }\end{array}$ & Arakawa B grid & Arakawa $\mathrm{C}$ grid \\
\hline $\begin{array}{l}\text { Time integration } \\
\text { scheme }\end{array}$ & $\begin{array}{l}\text { Leap-frog scheme with time } \\
\text { splitting technique }\end{array}$ & $\begin{array}{l}\text { Runge-Kutta 2nd } \& 3^{\text {rd }} \text { order time } \\
\text { splitting technique }\end{array}$ \\
\hline Radiation scheme & $\begin{array}{l}\text { Dudhia's shortwave/longwave } \\
\text { simple cloud }\end{array}$ & $\begin{array}{l}\text { Dudhia's shortwave } \\
\text { longwave }\end{array}$ \\
\hline heme & MRF & YSU \\
\hline $\begin{array}{l}\text { Cumulus } \\
\text { parameterization } \\
\text { scheme }\end{array}$ & Kain Fritsch & Kain Fritsch \\
\hline Microphysics & Simple ice & Ferrier \\
\hline
\end{tabular}

To analyze the intensity, structure and track of TC Sidr, the MM5 and WRF models were run for $96 \mathrm{~h}$ with the initial field on at 13 November, 2007 and the models simulated data were compared with those obtained from Joint Typhoon Warning Centre (JTWC). The National Center for Environmental Prediction (NCEP) FNL reanalysis data $\left(1^{\circ} \mathrm{X} 1^{\circ}\right.$ horizontal resolution) are used to provide the initial and lateral boundary conditions respectively to all the models. 


\section{Synoptic situation of Tropical Cyclone Sidr (09-16 November 2007)}

A low pressure area formed over southeast of the Andaman Islands with a weak lowlevel circulation near the Nicobar Islands on 9 November, 2007 moved to northnorthwesterly direction initially and intensified into a well-marked low over the same area. Depression over the southeast Bay of Bengal and adjoining Andaman Sea and lay centered at $0900 \mathrm{UTC}$ on 11 November, 2007 near $10.0{ }^{\circ} \mathrm{N}$ and $92.0{ }^{\circ} \mathrm{E}$ about $200 \mathrm{~km}$ south-southwest of Port Blair and the system is likely to intensify further and moved in a west north westerly direction. The depression moved further north northwest and transformed to deep depression (DD) and lay centered $10.5{ }^{\circ} \mathrm{N}$ and $91.5^{\circ} \mathrm{E}$ at 1800 UTC on the same day. The system further intensified into cyclonic storm as on 0300 UTC on 12 November and severe cyclonic storm (SCS) as on 1200 UTC on the same day and lay centered at $11.5^{\circ} \mathrm{N}$ and $90{ }^{\circ} \mathrm{E}$ and moved northerly direction. The system attained into a very severe cyclonic storm (VSCS) with the central MSLP of $986 \mathrm{hPa}$, the MWS of $33 \mathrm{~m} / \mathrm{s}$ and the central location at about $11.5^{\circ} \mathrm{N}$ and $90.0^{\circ} \mathrm{E}$ at around 1800 UTC on 12 November. The VSCS 'Sidr' moved in the same direction and intensified further and at 0300 UTC on 15 November its central MSLP lowered to $944.0 \mathrm{hPa}$, the MWS increased to $58.8 \mathrm{~m} / \mathrm{s}$ when its central location was at about 18.0 ${ }^{\circ} \mathrm{N}$ and $89.0{ }^{\circ} \mathrm{E}$. Then, the VSCS 'Sidr' moved continuously north wards finally crossed Bangladesh coast at around 1600 UTC on 15 November, 2007. The observed track is depicted in Fig. 1.

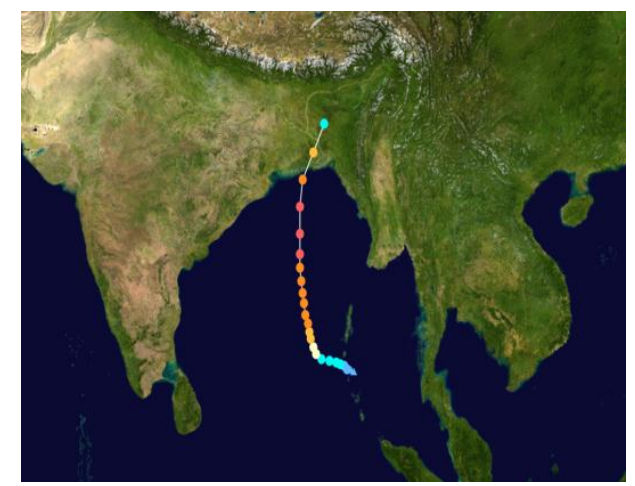

Fig. 1. Observed track of TC Sidr.

\section{Results and Discussion}

To analyze the evolution and structure of TC Sidr, the MM5 and WRF model were run for $96 \mathrm{~h}$ with the initial field at 00 UTC on 13 November, 2007. Different meteorological parameters obtained from both the models are discussed for the evolution and structure of the TC Sidr in the following sub-section. Model simulated results are compared with available data obtained from Joint Typhoon Warning Centre 
(JTWC). Models output are taken at $3 \mathrm{~h}$ intervals and plotted by Grid Analysis and Display System (GrADS) software.

\subsection{Pressure field}

Minimum seal level pressure (MSLP) of a TC is of great importance as it helps to measure the intensity of a TC. Fig. 2a shows the observed and model simulated MSLP of TC Sidr. It appears from the Fig. 2a that the MM5 model simulated MSLP gradually drops (without any oscillation) with time and attains peak intensity with minimum pressure $961 \mathrm{hPa}$ at $00 \mathrm{UTC}$ on 15 November, 2007 and thereafter MSLP increases gradually. Finally just before the landfall the MSLP is $966 \mathrm{hPa}$ at $12 \mathrm{UTC}$ on 15 November, 2007. Again, WRF model simulated MSLP gradually drops (having little bit oscillation) with time and attains peak intensity with minimum pressure 977 $\mathrm{hPa}$ at 03,15 and $18 \mathrm{UTC}$ on 15 November, 2007 and thereafter MSLP increases gradually. Finally just before the landfall the MSLP is $987 \mathrm{hPa}$ at $00 \mathrm{UTC}$ on 16 November, 2007. On the other hand, the observed MSLP $918 \mathrm{hPa}$ is obtained at 18 UTC on 14 November and remain same up to 06 UTC on 15 November, 2007 and thereafter MSLP increases gradually. Landfall of the system occurs at 12 UTC on 15 November with observed value of MSLP $926 \mathrm{hPa}$. It is noted that landfall time obtained from MM5 model simulation is same to that of observed but landfall time obtained from WRF model is different from that of observed. Again, at the landfall position, MSLPs are different for model simulated and observed cases. The variation of model simulated MSLP compare to that of observed with time shows that both the models simulate realistic temporal variation of MSLP but simulated values are higher than observed values.

The distribution of sea level pressures (SLP) for the TC Sidr at 00 UTC on 13-15 November and 12 UTC on 15 November, 2007 (i.e. before landfall) for MM5 model and at 00 UTC on 13, 14, 15 and 16 November, 2007 (i.e. before landfall) for WRF model have been shown in Figs. 2b and 2c respectfully. Figure demonstrate that the intensity of the TC increases as the MSLP drops with time up to its peak intensity and TC changes its position with time. The isobar has circular arrangement around the TC centre with some asymmetric features in the outer periphery. The contour interval is different in magnitude for different position because of different intensity of the system. At mature stage the contour intervals are 5 and $3 \mathrm{hPa}$ obtained from MM5 and WRF model respectively. Using MM5 model, the lowest simulated MSLP (961 hPa) is obtained at 00 UTC on 15 November (Fig. 2a). But just before the landfall at 12 UTC on 15 November, 2007 simulated MSLPs is $966 \mathrm{hPa}$. At this stage, considering the outermost closed isobar, the system's horizontal size is estimated as $8.0^{\circ}$ in the eastwest and $9.5^{\circ}$ in the north-south direction demonstrating a little bit spatial asymmetry in its horizontal structure (Fig. 2b). Again, using WRF model, the lowest simulated MSLP $(977 \mathrm{hPa})$ at the centre of the eye of the TC Sidr is found at 03 UTC on 15 November, 2007 (Fig. 2a). But at 00 UTC on 16 November, 2007 the simulated MSLP 


\section{Tropical Cyclone Sidr using Numerical Models}

of the centre is $987 \mathrm{hPa}$. At this stage, considering the outermost closed isobar, the system's horizontal size is estimated as $5.0^{\circ}$ in the east-west direction and $7.5^{\circ}$ in the north-south demonstrating a spatial asymmetry in its horizontal structure (Fig. 2c).

The distribution of the SLP of the TC Sidr along east-west cross section passing through its centre at $\left(20.541{ }^{\circ} \mathrm{N}\right.$ and $\left.90.734{ }^{\circ} \mathrm{E}\right)$ at time $12 \mathrm{UTC}$ on 15 November, 2007 for MM5 and through its centre at $\left(21.462^{\circ} \mathrm{N}\right.$ and $\left.89.453{ }^{\circ} \mathrm{E}\right)$ at time $00 \mathrm{UTC}$ on 16 November, 2007 have been shown in Figs. 2d and 2e respectively. The figures demonstrate the moderate pressure gradient around the centre with maximum gradient at around $15-20 \mathrm{~km}$ from the centre for both the models. Thus the radius of the TC eye is found to be below $15 \mathrm{~km}$ according to the simulation from both the models.

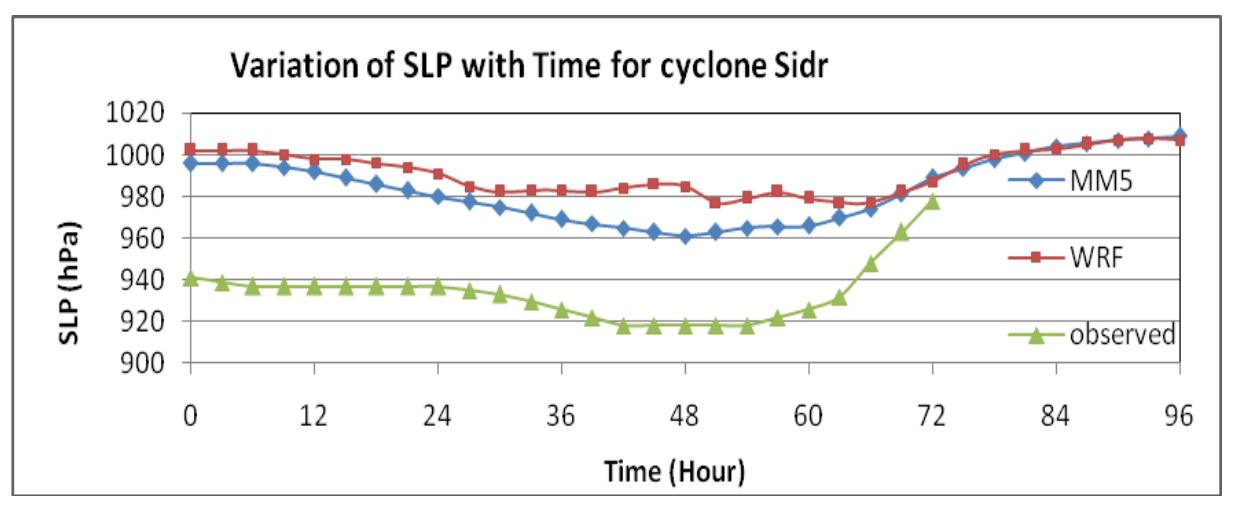

Fig. 2a. MM5 model simulated and observed central pressure of TC Sidr.
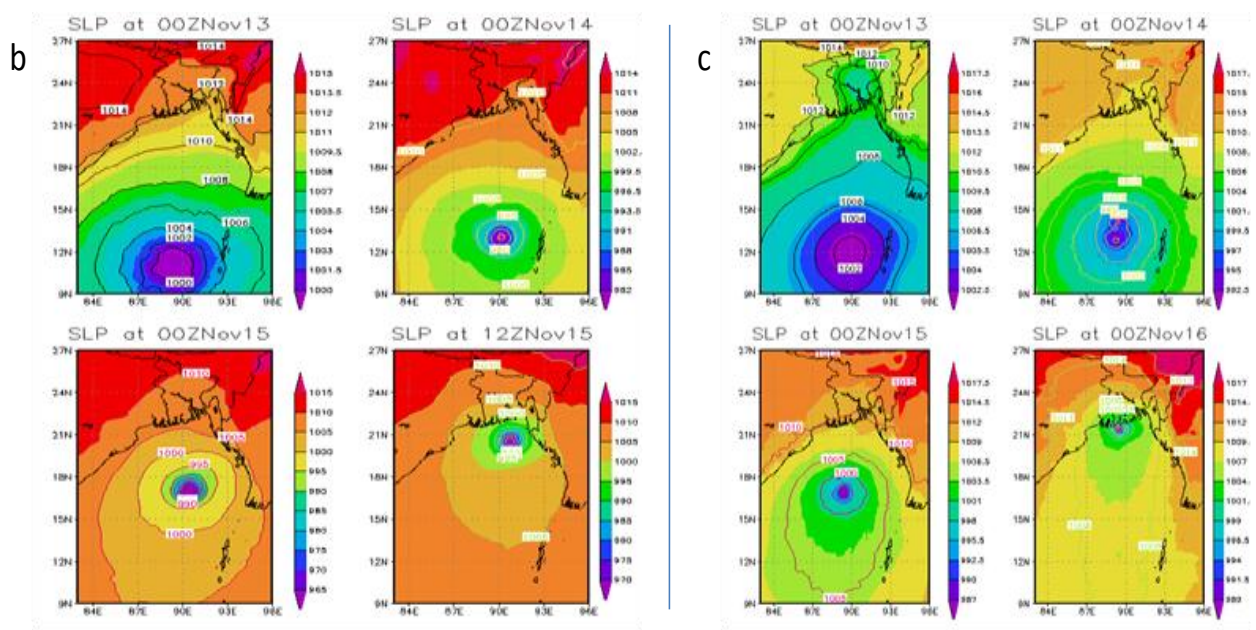

Fig. 2. (b) MM5 and (c) WRF Models simulated SLP of TC Sidr. 

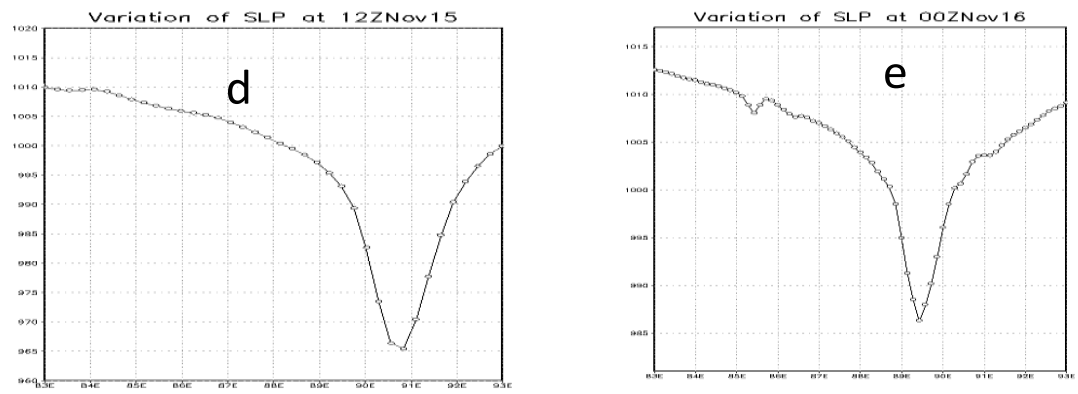

Fig. 2. East West cross sectional view of simulated SLP of TC Sidr obtained from (d) MM5 and (e) WRF models through the centre.

\subsection{Wind field}

Maximum wind speed (MWS) directly devastates the affected area at the time of landfall. Fig. 3a shows the temporal variations of MM5 and WRF model simulated MWS and observed winds of TC Sidr. The model simulated MWS are obtained at the standard meteorological height of $10 \mathrm{~m}$. The model simulated MWSs obtained from MM5 are lower than the observed values all through the simulated time except for the landfall time when the simulated values are almost matched with that observed value. Again, the model simulated MWSs obtained from WRF are higher than the observed values all through the simulated time. The simulated highest MWS is obtained at 00 UTC on 15 November for MM5 model and at 18 UTC on15 November for WRF where as that for observed is obtained at 18 UTC on 14 November, 2007 retains this value up to 18 UTC on 15 November, 2007.

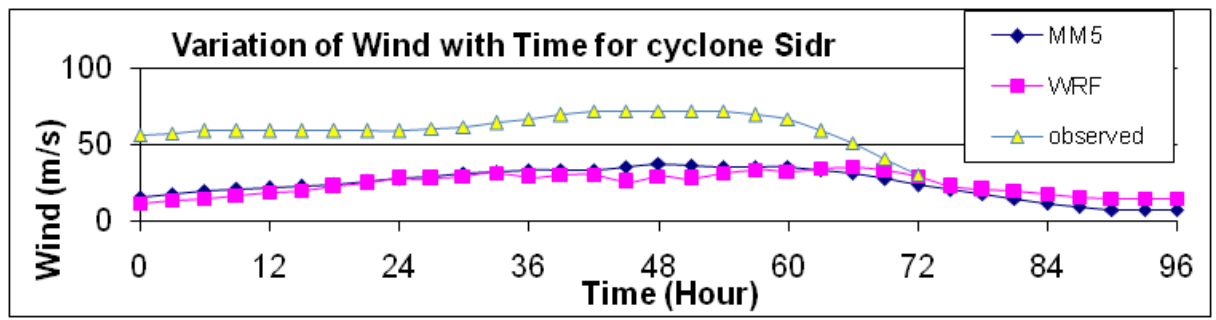

Fig. 3a. Observed and MM5 and WRF model simulated wind speed (m/s) of TC Sidr with time.

The distribution of surface $(10 \mathrm{~m})$ wind for the TC Sidr at different times for MM5 and WRF models are shown in Figs. $3 b$ and 3c. Figures show that the wind field of the TC is highly asymmetric in the horizontal distribution. At 00 UTC on 13 November, 2007 (i.e. at the initial time of simulation), when the TC was in the sea according to the simulated results from both the models, the pattern has an asymmetric wind 
distribution with strong wind bands in the front left and right sides, close to the centre of north directed moving storm. The wind flow in the core region shows a near circular feature with minimum wind speed at the centre. Maximum speed at this time is 16 and $12 \mathrm{~m} / \mathrm{s}$ for the MM5 and WRF models respectively. At 00 UTC on 14 and 15 November, 2007, TC is organized with strong wind band around and the wind flow in the core region shows asymmetric feature with minimum wind at the centre. Maximum winds at these stages are 27 and $35 \mathrm{~m} / \mathrm{s}$ for MM5 model and 27 and $30 \mathrm{~m} / \mathrm{s}$ for WRF model. For MM5 model, at 12 UTC on 15 November, 2007 (i.e. just before the landfall), a strong wind band (wind speed $>30 \mathrm{~m} / \mathrm{s}$ ) having strongest wind exceeding $35 \mathrm{~m} / \mathrm{s}$ is found around the system centre. It may be noted that the model has generated lower winds of $36 \mathrm{~m} / \mathrm{s}(130 \mathrm{~km} / \mathrm{h})$ than the observed winds of around $140 \mathrm{~km} / \mathrm{h}$ but just before landfall (i.e. at 12 UTC on 15 November, 2007) both simulated and observed winds are close to each other (Fig. 3b). Fig. 3b shows the landfall feature of surface wind distribution where the winds is much less in the front side compared to other of the cyclonic system. It is due to frictional force of landmass. Similar feature is seen for WRF model at 00 UTC on 16 November, 2007 but the maximum wind speed obtained from WRF model is smaller to that of MM5 model (Fig. 3c).

b
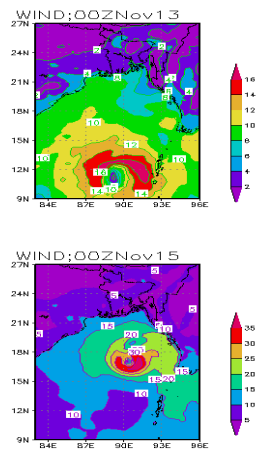
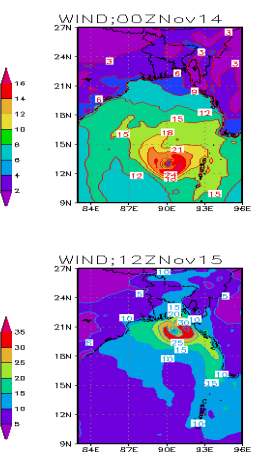
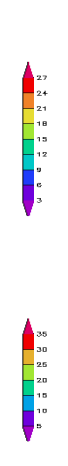
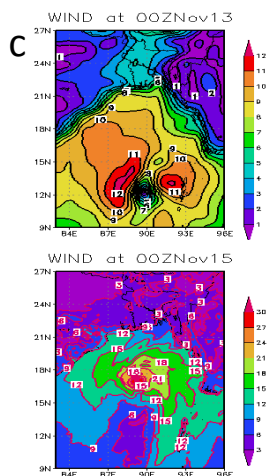
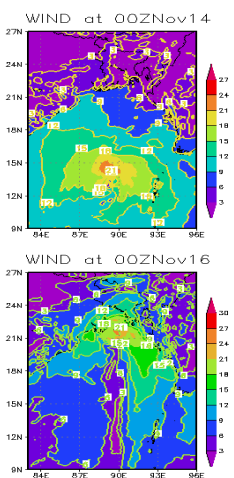

Fig. 3. (b) MM5 and (c) WRF models simulated Wind speed (m/s) TC Sidr at $10 \mathrm{~m}$.

The distribution of the surface wind of the TC Sidr along east-west cross section passing through its centre $\left(20.54{ }^{\circ} \mathrm{N}\right.$ and $\left.89.453{ }^{\circ} \mathrm{E}\right)$ at $12 \mathrm{UTC}$ on 15 November, 2007 for MM5 model and at centre $\left(21.462^{\circ} \mathrm{N}\right.$ and $\left.89.453{ }^{\circ} \mathrm{E}\right)$ at $00 \mathrm{UTC}$ on 16 November, 2007 for WRF model are shown in Figs. 3d and 3e respectively. Figures demonstrate that a calm region is found inside the eye of the system and maximum wind is found in the eye wall. The radius of maximum wind of the TC Sidr is found to be just lower than $70 \mathrm{~km}$ according to the simulations.

The horizontal distribution of vector and magnitude of the wind field for 850, 500, 300 and $200 \mathrm{hPa}$ at $12 \mathrm{UTC}$ on 15 November, 2007 (i.e. before landfall) for MM5 and 00 UTC on 16 November, 2007 (i.e. before landfall) for WRF model have been shown in Figs. $3 \mathrm{f}$ and $3 \mathrm{~g}$ respectively. Figures show that a well organized cyclonic circulation 
with strong winds encircling the centre is found at 850 and $500 \mathrm{hPa}$ levels. At $300 \mathrm{hPa}$ wind shows little bit cyclonic circulation in the right side of the TC and weak outflow in the left side. At $200 \mathrm{hPa}$ level strong outflow is evident from the central part of the TC except at 00 UTC on 13 November, 2007 (i.e. at initial time not shown in Fgure). Model derived maximum winds obtained from MM5 and WRF models for different times are tabulated in Table 2. MM5 model derived maximum winds obtained just before landfall (12 UTC on 15 November, 2007) are about 60, 50, 50 and $25 \mathrm{~m} / \mathrm{s}$ at $850,500,300$ and $200 \mathrm{hPa}$ levels respectively. Again, WRF model derived maximum winds just before landfall (00 UTC on 16 November, 2007) are about 50, 40, 30 and $20 \mathrm{~m} / \mathrm{s}$ at 850, 500, 300 and $100 \mathrm{hPa}$ levels respectively. Magnitude of wind obtained from WRF model is higher than that obtained from MM5 model. It is noted that the strong wind is confined to the right of the direction of the movement of the system. So, model derived results shown in Fig. 3f-g satisfy the inflow in the lower levels and outflow in the upper levels.
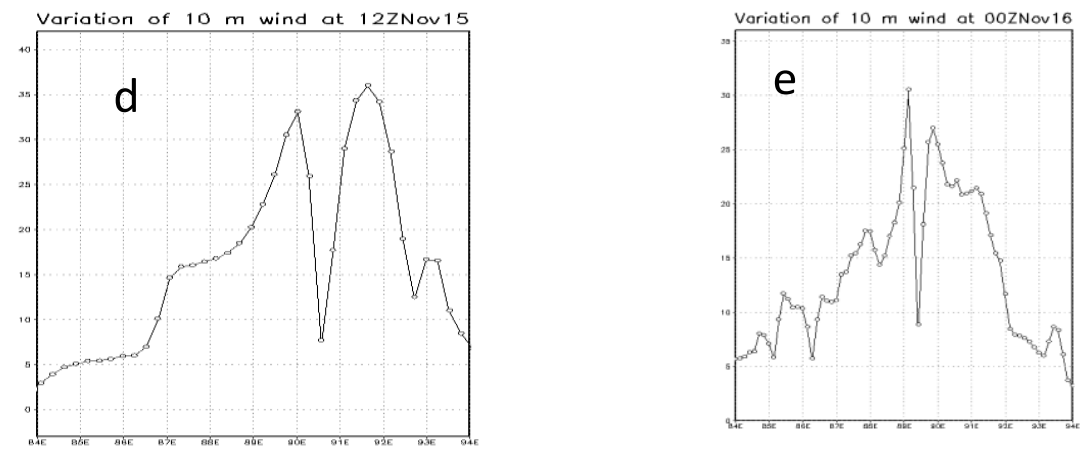

Fig. 3. East West cross sectional view of (d) MM5 and (e) WRF models simulated wind speed $(\mathrm{m} / \mathrm{s})$ of TC Sidr along the centres.

Table 2. MM5and WRFmodels simulated wind speed $(\mathrm{m} / \mathrm{s})$ at different pressure levels of TC Sidr.

\begin{tabular}{|c|c|c|c|c|c|c|}
\hline \multirow[t]{2}{*}{ Model } & \multirow{2}{*}{$\begin{array}{l}\text { Pressure } \\
\text { level }\end{array}$} & \multicolumn{5}{|c|}{ Wind Speed $(\mathrm{m} / \mathrm{s})$ at } \\
\hline & & 00 UTC & 00 UTC & 00 UTC & 12 UTC & 00 UTC \\
\hline & & 13 & 14 & 15 & 15 & 16 \\
\hline & & November & November & November & November & November \\
\hline \multirow[t]{4}{*}{ MM5 } & 850 & 20 & 40 & 60 & 60 & -------.- \\
\hline & 500 & 20 & 30 & 50 & 50 & -------. \\
\hline & 300 & 40 & 40 & 40 & 50 & ------- \\
\hline & 200 & 50 & 60 & 50 & 50 & -------. \\
\hline \multirow[t]{4}{*}{ WRF } & 850 & 20 & 40 & 50 & -------- & 50 \\
\hline & 500 & 20 & 40 & 50 & ------- & 40 \\
\hline & 300 & 40 & 40 & 40 & ------- & 30 \\
\hline & 200 & 50 & 50 & 50 & ------.- & 40 \\
\hline
\end{tabular}



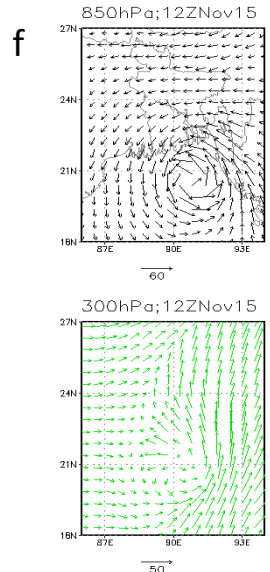
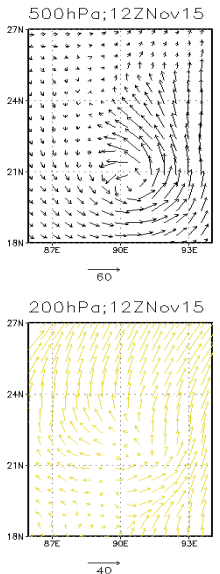

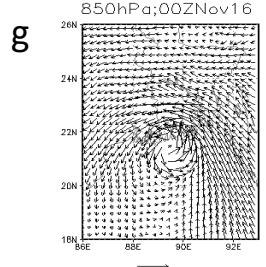

$\overrightarrow{50}$

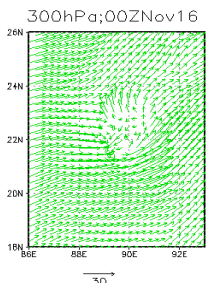

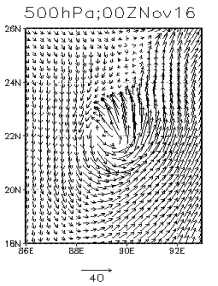

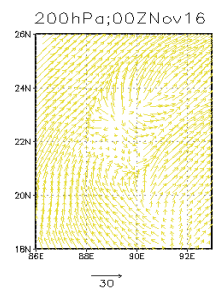

Fig. 3. (f) MM5 and (g) WRF models simulated wind vector at $850,500,300$ and $200 \mathrm{hPa}$ levels.

Figs. $3 \mathrm{~h}$ and $3 \mathrm{i}$ show the vertical profile of radial wind, tangential wind, vertical velocity and horizontal wind of the system at 12 UTC on 15 November, 2007 (i.e. just before landfall) for MM5 model and 00 UTC on 16 November, 2007 (i.e. just before landfall) for WRF model respectively. MM5 and WRF model simulated radial wind, tangential wind, vertical velocity and horizontal wind $(\mathrm{cm} / \mathrm{s})$ of TC Sidr at different times are tabulated in the in the Table 3.

$\mathrm{h}$
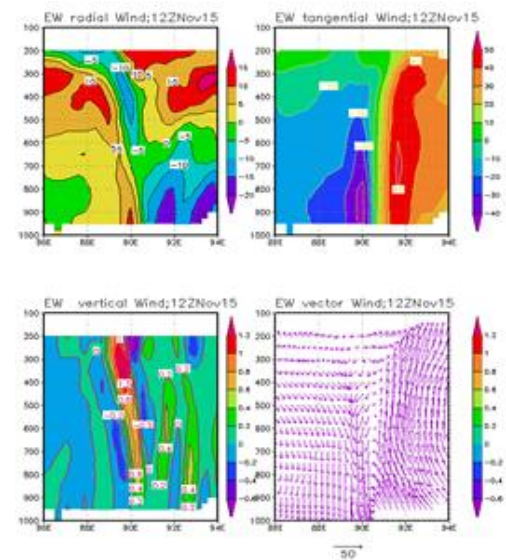

i
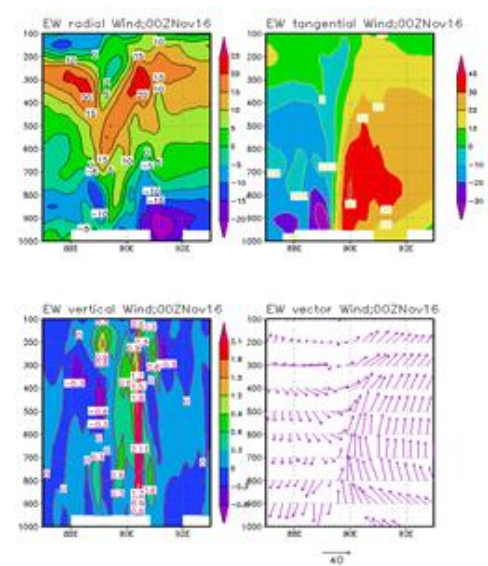

Fig. 3. (h) MM5 and (i) WRF models simulated east-west cross section of vertical structure of radial wind, tangential wind, vertical velocity and horizontal wind of TC Sidr along the centre.

The system is much more organized except at 00 UTC on 13 November, 2007 (i.e. at initial time; not shown in Figure) and it is also clearly showed that the system has 
strong inflow in the lower level which brings the air to the system through the boundary level and lower level and outflow in the upper level.

Figs. $3 \mathrm{~h}$ and $3 \mathrm{i}$ demonstrate that the tangential wind flows towards northerly direction at the eastern side of the system and southerly direction at the western side. The strong wind with different speed (tabulated in Tables 3) is confined to the different levels in the lower troposphere and extended up to $200 \mathrm{hPa}$ level at right and left side of the system.

From the Table 3, it is seen that the values of vertical motion are different in magnitude for different time and it reveals that strong upward motion of about 120 $\mathrm{cm} / \mathrm{s}$ at $12 \mathrm{UTC}$ on 15 November, 2007 for MM5 model and about $200 \mathrm{~cm} / \mathrm{s}$ at 00 UTC on 15 November, 2007 for WRF model exists along the eye wall and other parts of the system which feed moisture into the system. It is noted that Sidr has very strong updraft motion at the eye wall throughout mid and upper troposphere. In general downward motion is not strong. The downward motion is visible in the central parts of the TC and other areas of small pockets, which could be due to subsidence associated with convection.

Table 3. MM5 and WRF models simulated radial wind, tangential wind, vertical velocity and horizontal wind $(\mathrm{cm} / \mathrm{s})$ of TC Sidr.

\begin{tabular}{|c|c|c|c|c|c|c|}
\hline \multirow{4}{*}{ Model } & \multirow{4}{*}{$\begin{array}{l}\text { Component } \\
\text { of wind }\end{array}$} & \multicolumn{5}{|c|}{ Simulated wind speed $(\mathrm{cm} / \mathrm{s})$ at } \\
\hline & & 00 UTC & $00 \mathrm{UTC}$ & $00 \mathrm{UTC}$ & 12 UTC & 00 UTC \\
\hline & & & 14 & 15 & & \\
\hline & & November & November & November & November & November \\
\hline \multirow[t]{4}{*}{ MM5 } & Radial wind & 1200 & 1200 & 1500 & 2000 & --.---.- \\
\hline & $\begin{array}{l}\text { Tangential } \\
\text { wind }\end{array}$ & 1500 & 3000 & 5000 & 5000 & ------. \\
\hline & $\begin{array}{l}\text { Vertical } \\
\text { velocity }\end{array}$ & 50 & 60 & 80 & 120 & ------- \\
\hline & $\begin{array}{l}\text { Horizontal } \\
\text { wind }\end{array}$ & 2000 & 4000 & 5000 & 5000 & ------- \\
\hline \multirow[t]{4}{*}{ WRF } & Radial wind & 800 & 12 & 2500 & -------. & 2500 \\
\hline & $\begin{array}{l}\text { Tangential } \\
\text { wind }\end{array}$ & 18 & 2500 & 3000 & ------- & 3000 \\
\hline & $\begin{array}{l}\text { Vertical } \\
\text { velocity }\end{array}$ & 0.40 & 70 & 200 & -------- & 140 \\
\hline & $\begin{array}{l}\text { Horizontal } \\
\text { wind }\end{array}$ & 2000 & 2000 & 4000 & -------- & 4000 \\
\hline
\end{tabular}

From the Table 3, it is seen that the values of horizontal wind at different times are different. Fig. 3h-i show the distribution of strong winds up to $200 \mathrm{hPa}$ around the centre of TC at 12 UTC on 15 November, 2007 for MM5 and 00 UTC on 16 November, 2007 for WRF model along the centre of the system. It further confirms that the maximum winds are confined to the right quadrant of the direction of movement of the system. This value decreases with the radial distance from both sides of the eye. Calm wind zone is sharp and narrow and little bit tilted to the west and get expanded towards upper levels. Cyclonic circulation is generally seen up to about 300 
$\mathrm{hPa}$ level and anticyclonic circulation with divergence fields aloft. This is in agreement with the previous studies studies [12,13]. In this case cyclonic circulation is also seen up to about $350 \mathrm{hPa}$ level for MM5 model and up to $300 \mathrm{hPa}$ for WRF model and anticyclonic circulation with divergence fields aloft.

\subsection{Vorticity field}

To know the evolution, the plot of MM5 and WRF models simulated low level relative vorticity at $850 \mathrm{hPa}$ as a function of time is shown in Fig. 4a.The analysis reveals that there is a gradual rise in the vorticity value in the first $60 \mathrm{~h}$ of the simulation of MM5 model and thereafter the value shows a falling tendency up to $96 \mathrm{~h}$ of model run. Again output from WRF model reveals that there is a gradual rise of vorticity in the first $24 \mathrm{~h}$ of simulation of the model and then sustains the maximum value with little bit lower value by making several oscillations for next $42 \mathrm{~h}$ duration (24-66 h of forecast). Thereafter the value shows a rapid fall.

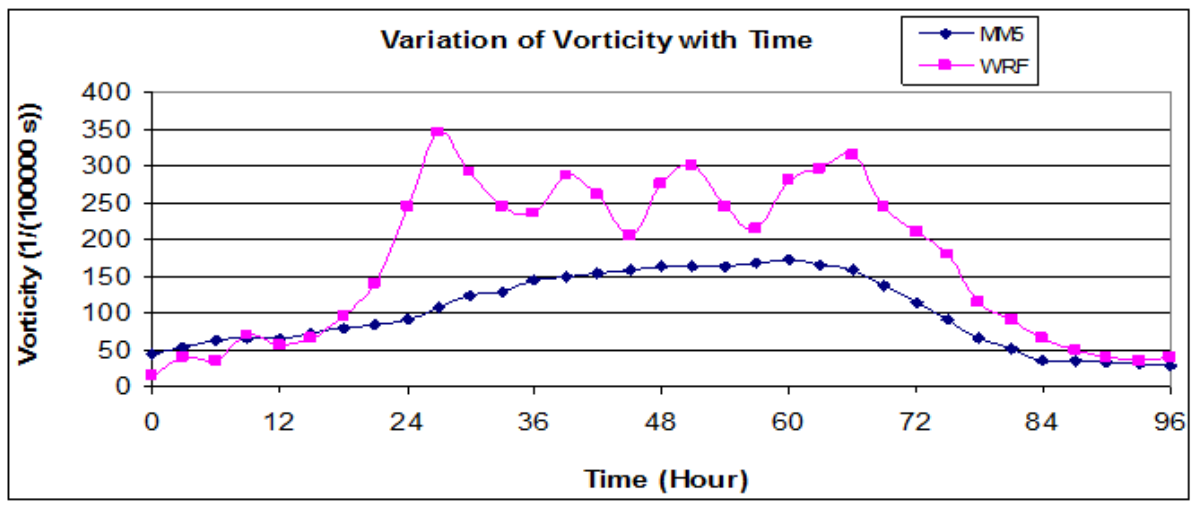

Fig. 4a. Evolution of MM5 and WRF models simulated vorticity with time of TC Sidr.

The horizontal distribution of the relative vorticity obtained from MM5 model at 12 UTC on 15 November, 2007 (i.e. before landfall) and obtained from WRF model at 00 UTC on 16 November, 2007 (i.e. before landfall) of TC Sidr at 850, 500, 300 and $200 \mathrm{hPa}$ levels are shown in Figs. $4 \mathrm{~b}$ and $4 \mathrm{c}$ respectively

It is seen from the Figs. $4 \mathrm{~b}$ and $4 \mathrm{c}$ that the vorticity obtained from MM5 and WRF models is distributed with maximum value at the centre and these values are tabulated in Table 4 for MM5 and WRF model. From Table 4, it is clear that these values increased with the advance of time except at 12 UTC on 15 November, 2007 (i.e. before landfall) for MM5 model and 00 UTC on 16 November, 2007 (i.e. just before landfall) for WRF model at different levels. This is due to landmass effect before landfall. The distribution maintains circular pattern with some asymmetric features in 
the outer periphery except at 00 UTC on 13 November, 2007 (i.e. initial time) for both models where symmetrical circular pattern is available at all levels.

b

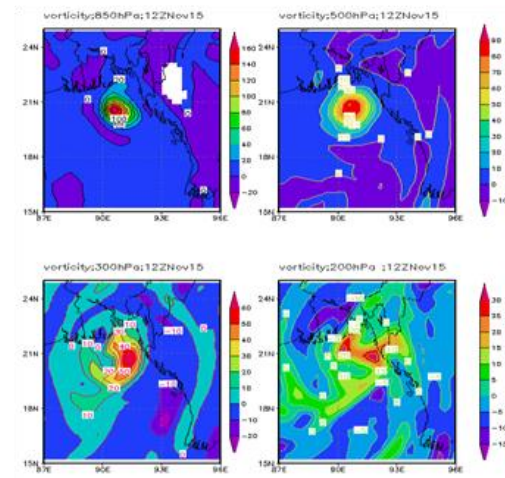

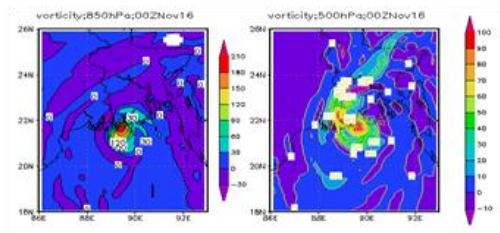

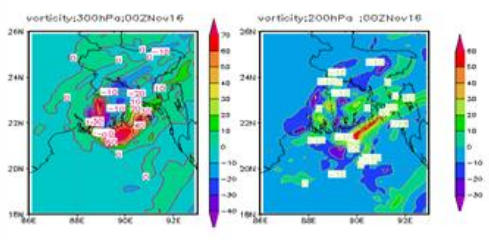

Fig. 4. (b) MM5 and (c) WRF models simulated vorticity field associated with Sidr at 850, 500, 300 and $200 \mathrm{hPa}$ levels.

At $850 \mathrm{hPa}$ level, (Figs. 4b and 4c) negative vorticity fields are found almost in all sides of the centre of the TC which is followed by a positive and negative vorticity fields at 12 UTC on 15 November, 2007 (i.e. just before the landfall). Similar phenomena of negative vorticity are found at 00 UTC on 13-15 November, 2007 (not shown in Fig.). The distance of the negative vorticity from the centre increased due to the intensification of the intensity of TC (not shown). Low level relative vorticity fields confirm the strong cyclonic circulation with different values of the radius at different time in feeding moisture into the system to sustain its intensity.

At 500 and $300 \mathrm{hPa}$ levels the distribution of relative vorticity shows a symmetric character in the horizontal direction. The values of relative vorticity increased with the intensification of the intensity of the cyclone and then decreased before landfall at time 12 UTC on 15 November for MM5 model and after landfall at 00 UTC on 16 November, 2007 at $500 \mathrm{hPa}$ level. But the values of relative vorticity increased with the development of TC at all stages at $300 \mathrm{hPa}$ level. At $200 \mathrm{hPa}$ level, the weak positive vorticity embedded with negative vorticity field is visible at $200 \mathrm{hPa}$ level. Negative vorticity is found at or near the centre.

Vertical distribution of relative vorticity through the centre in the east-west direction is shown in Figs. 4d and 4e for models MM5 and WRF and values are tabulated in the Table 4.

According to the output obtained from MM5 model at 00 UTC on 13 November (i.e. the initial time), the positive vorticity is spread over a horizontal distance with strong vorticity at slightly western side of the centre $\left(11.042{ }^{\circ} \mathrm{N}\right.$ and $\left.89.588^{\circ} \mathrm{E}\right)$. This pattern of distribution extends from surface to around $200 \mathrm{hPa}$ level with the exception that the magnitude of the vorticity decreases with height. Similar pattern with higher positive value of vorticity is found at the centre after $24 \mathrm{~h}$ of simulation at $00 \mathrm{UTC}$ on 
14 November, 2007 along the centre $\left(13.044^{\circ} \mathrm{N}\right)$. At 00 UTC on 15 November, 2007, the system has the positive vorticity along the centre $\left(17.134^{\circ} \mathrm{N}\right)$ up to $200 \mathrm{hPa}$ with highest positive value of vorticity. At 12 UTC on 15 November, 2007, the system has the same value of positive vorticity as the previous time at 00 UTC on 15 November, 2007 along the centre $\left(20.541^{\circ} \mathrm{N}\right)$ up to $200 \mathrm{hPa}$.

Table 4. MM5 and WRF Models simulated maximum vorticity $\left(\times 10^{-5} \mathrm{~s}^{-1}\right)$ of TC Sidr.

\begin{tabular}{|c|c|c|c|c|c|c|}
\hline \multirow{4}{*}{ Model } & \multirow{4}{*}{ Pressure level } & \multicolumn{5}{|c|}{ Wind Speed $(\mathrm{m} / \mathrm{s})$ at } \\
\hline & & $00 \mathrm{UTC}$ & 00 UTC & $00 \mathrm{UTC}$ & 12 UTC & 00 UTC \\
\hline & & 13 & 14 & 15 & & \\
\hline & & November & November & November & November & November \\
\hline \multirow[t]{5}{*}{ MM5 } & 850 & 45 & 90 & 160 & 160 & -------- \\
\hline & 500 & 35 & 55 & 100 & 90 & -------- \\
\hline & 300 & 20 & 40 & 60 & 60 & -------- \\
\hline & 200 & 15 & 20 & 50 & 30 & -------- \\
\hline & $\begin{array}{l}\text { Vertical } \\
\text { distribution }\end{array}$ & 35 & 60 & 160 & 160 & \\
\hline \multirow[t]{5}{*}{ WRF } & 850 & 18 & 240 & 270 & -------- & 210 \\
\hline & 500 & 15 & 240 & 140 & -------- & 100 \\
\hline & 300 & 12 & 180 & 120 & -------.- & 70 \\
\hline & 200 & 10 & 80 & 70 & ------.- & 60 \\
\hline & $\begin{array}{l}\text { Vertical } \\
\text { distribution }\end{array}$ & 18 & 80 & 270 & & 210 \\
\hline
\end{tabular}
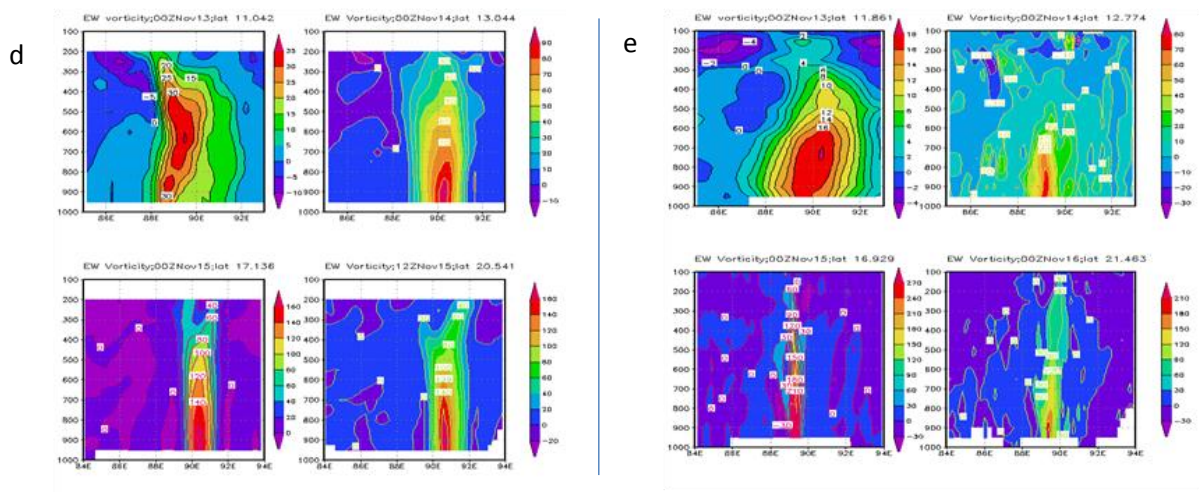

Fig. 4. (d) MM5 and (e) WRF models simulated vertical distribution of relative vorticity field in the east-west direction of TC Sidr.

Again, according to the output obtained from WRF model at 00 UTC on 13 November (i.e. the initial time), the positive vorticity is spread over a horizontal distance with strong vorticity at slightly eastern side of the centre $\left(11.861{ }^{\circ} \mathrm{N}\right.$ and $\left.89.868^{\circ} \mathrm{E}\right)$. This pattern of distribution extends from surface to around $150 \mathrm{hPa}$ level with the exception that the magnitude of the vorticity decreases with height. Similar pattern with higher positive vorticity is found at the centre after $24 \mathrm{~h}$ of simulation at 00 UTC on 14 November, 2007 along the centre $\left(12.774{ }^{\circ} \mathrm{N}\right)$. At 00 UTC on 15 
November, 2007, the system has the positive vorticity along the centre $\left(16.929^{\circ} \mathrm{N}\right)$ up to $200 \mathrm{hPa}$ level with highest positive value. At 00 UTC on 16 November, 2007, the system has less positive vorticity than the previous time at 00 UTC on 15 November, 2007 along the centre $\left(21.463^{\circ} \mathrm{N}\right)$ up to $150 \mathrm{hPa}$ with low magnitude. It may be effect of landmass before landfall.

\subsection{Temperature anomaly}

The MM5 model simulated temperature anomaly of TC Sidr at 00 UTC on 13-15 November and 12 UTC on 15 November, 2007 (i.e. before landfall) from surface to $100 \mathrm{hPa}$ level is shown in Fig. 5a and temperature anomaly is tabulated in Table 5. At 00 UTC on 13 November, 2007, warm core of $10^{\circ} \mathrm{C}$ is simulated at $950-200 \mathrm{hPa}$ layer. It is noted that the warm core region is slightly expanded outward at $800-300 \mathrm{hPa}$ level. The greatest anomaly has occurred around $450 \mathrm{hPa}$ level. Negative temperature anomalies are also shown in the upper levels. At 00 UTC of 14 November, 2007, warm core of $12^{\circ} \mathrm{C}$ is simulated at $950-200 \mathrm{hPa}$ layer. It is noted that the warm core region is expanded outward at $700-350 \mathrm{hPa}$ level. The greatest anomaly is simulated by the MM5 model around 500 hPalevel. At 00 UTC on 15 November, 2007, $14^{\circ} \mathrm{C}$ warm core is observed at $950-200 \mathrm{hPa}$ layer. It is noted that the warm core region is expanded outward at $600-350 \mathrm{hPa}$ level. The greatest anomaly is simulated around 400 hPalevel. At 12 UTC on 15 November, 2007, warm core $11^{\circ} \mathrm{C}$ is observed in 950-200 $\mathrm{hPa}$ layer. It is noted that the warm core region is expanded outward at $650-300 \mathrm{hPa}$ level. The greatest anomaly is simulated around $500 \mathrm{hPa}$ level. The simulated temperature anomaly demonstrates that the warm core is visible mainly in the upper troposphere during 13-15 November, 2007. Negative temperature anomalies at lower levels are due to contamination by heavy precipitation at 00 UTC and 12 UTC of 15 November, 2007.

Table 5. MM5 and WRF Models simulated temperature anomaly $\left({ }^{\circ} \mathrm{C}\right)$ associated with TC Sidr.

\begin{tabular}{llllll}
\hline Model & \multicolumn{2}{l}{ Temperature anomaly $\left({ }^{\circ} \mathrm{C}\right)$ at } & & \\
& 00 UTC on & 00 UTC on & 00 UTC on & 12 UTC on & 00 UTC on \\
& 13 November & 14 November & 15 November & 15 November & 16 November \\
\hline MM5 & 10 & 12 & 14 & 11 & --------- \\
WRF & 10 & 8 & 10 & --------- & 8 \\
\hline
\end{tabular}

Again, the WRF model simulated temperature anomaly of TC Sidr at 00 UTC on 13-16 November, 2007 from surface to $100 \mathrm{hPa}$ level are shown in Fig. 5b and values are tabulated in Table 5. At 00 UTC on 13 November, $2007,10^{\circ} \mathrm{C}$ warm core is observed in the layer between $950-350 \mathrm{hPa}$. It is noted that the warm core region is slightly expanded outward at $750-350 \mathrm{hPa}$ level. The greatest anomaly is found around $450 \mathrm{hPa}$ level. The simulated temperature anomaly demonstrates that the warm core is visible mainly in the upper troposphere. Negative temperature anomalies are seen at 
the upper levels. At $00 \mathrm{UTC}$ on 14 November, $2007,8^{\circ} \mathrm{C}$ warm core is observed in the layer between $950-300 \mathrm{hPa}$. It is noted that the warm core region is expanded outward at $700-300 \mathrm{hPa}$ level. The greatest anomaly is found around $450 \mathrm{hPa}$ level. The simulated temperature anomaly demonstrates that the warm core is visible mainly in the upper troposphere. At $00 \mathrm{UTC}$ on 15 November, $2007,10^{\circ} \mathrm{C}$ warm core is observed in the layer between $950-200 \mathrm{hPa}$. It is noted that the warm core region is expanded outward at 850-200 hPa level. The greatest anomaly is found around 450 $\mathrm{hPa}$ level. The simulated temperature anomaly demonstrates that the warm core is visible mainly at upper troposphere. At $00 \mathrm{UTC}$ on 16 November, $2007,8^{\circ} \mathrm{C}$ warm core is observed in the layer between $950-300 \mathrm{hPa}$. The warm core region is expanded outward at 700-300 hPa level. The greatest anomaly is seen around $550 \mathrm{hPa}$ level. The simulated temperature anomaly demonstrates that the warm core is visible mainly at upper troposphere. Negative temperature anomalies at lower levels are due to effect of heavy precipitation.

a
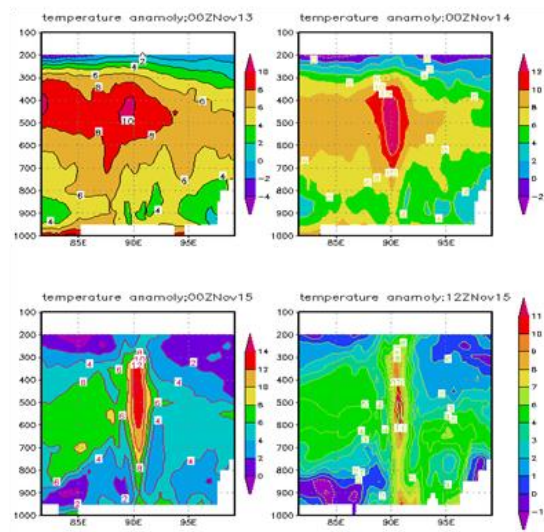

b
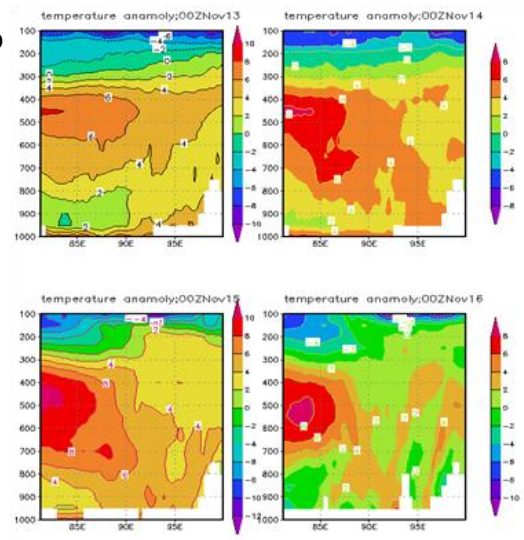

Fig. 5. (a) MM5 and (b) WRF models simulated vertical distribution of temperature anomaly in the east-west cross section of TC Sidr through the centre.

\subsection{Track pattern and landfall time and position}

MM5 and WRF models simulated track of TC Sidr along with observed track are plotted in the Fig. 6a-b. The track forecasts of TC Sidr for 96, 7248 and $24 \mathrm{~h}$ are based on the initial fields of 00 UTC on 13 November, 00 UTC on 14 November, 00 UTC on 15 November and 12 UTC of 15 November, 2007 respectively.

It is seen from Fig. 6a that MM5 model simulated track for 96, 72, 48 and $24 \mathrm{~h}$ are parallel to the observed track but it is deviated to east and west side of the observed track. It may be because of initial data error. This Figure shows that model is able to generate northwest, north and northeast movement of the system very well. It reveals that 24, 48 and $72 \mathrm{~h}$ tracks are more close to the JTWC best track compared to $96 \mathrm{~h}$ tracks. However, there are some errors in the positions with respect to time which 
shows some lag in landfall. The track from $24 \mathrm{~h}$ simulation track is better than that of any others simulation. The landfall position for $24 \mathrm{~h}$ simulation track is much closer to any other simulation. So, by changing initial data, the simulated track becomes close to the observed track.
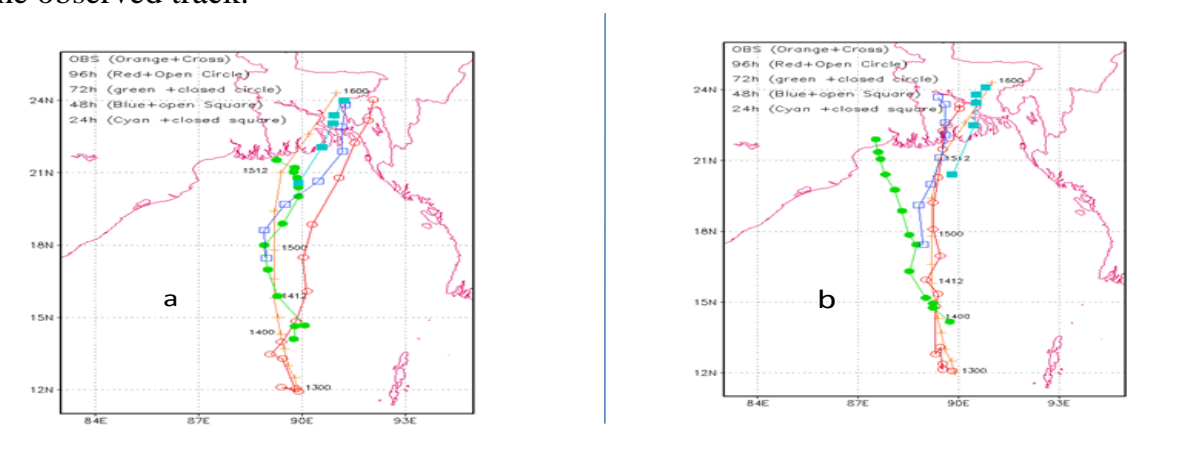

Fig. 6. (a) MM5 and (b) WRF Model simulated and observed tracks of TC Sidr.

It is seen from Fig. $6 \mathrm{~b}$ that WRF model simulated track for 96, 72, 48 and $24 \mathrm{~h}$ are parallel to observed track but it is deviated east and west side of the observed track. It may be because of initial data error. It shows that model is able to generate northwest, north and northeast movement of the system very well. The track obtained from $96 \mathrm{~h}$ simulation are more close to the JTWC best track compared to the track obtained from 24, 48 and $72 \mathrm{~h}$ simulation. However, there are some errors in the positions with respect to time which shows some lag in landfall. Simulated landfall time is 00 UTC of 16 November compared to observed landfall time 18 UTC of 15 November using $96 \mathrm{~h}$ simulation of WRF model based on the initial condition 00 UTC of 13 November, 2007. The track from $96 \mathrm{~h}$ simulation is better than that of any other simulations. The landfall position for $96 \mathrm{~h}$ simulation track is matched with observed position. So, by changing initial data, the simulated track became close to the observed track.

Table 6a. Landfall point and time error during cyclone Sidr.

\begin{tabular}{llllllll}
\hline $\begin{array}{l}\text { Forecast } \\
\text { Hours }\end{array}$ & $\begin{array}{l}\text { obs/ } \\
\text { models }\end{array}$ & $\begin{array}{l}\text { initial } \\
\text { condition } \\
\text { date/Time } \\
\text { (UTC) }\end{array}$ & $\begin{array}{l}\text { landfall time } \\
\text { date/Time } \\
\text { (UTC) }\end{array}$ & $\begin{array}{l}\text { landfall } \\
\text { position } \\
\text { lat }^{\circ} \mathrm{N}\end{array}$ & lon $^{\circ} \mathrm{E}$ & $\begin{array}{l}\text { Error } \\
\text { Distance } \\
(\mathrm{km})\end{array}$ & $\begin{array}{l}\text { Time } \\
\text { (hours) }\end{array}$ \\
\hline & Obs & & 200711151600 & 21.83 & 89.80 & & \\
96 & MM5 & 200711130000 & 200711152000 & 22.54 & 91.65 & $203 \mathrm{e}$ & $4 \mathrm{D}$ \\
72 & & 200711140000 & 200711170000 & 21.53 & 89.26 & $60 \mathrm{w}$ & $33 \mathrm{D}$ \\
48 & & 200711150000 & 200711160100 & 22.20 & 91.20 & $155 \mathrm{e}$ & $10 \mathrm{D}$ \\
24 & & 200711151200 & 200711151800 & 22.07 & 90.58 & $87 \mathrm{e}$ & $2 \mathrm{D}$ \\
96 & WRF & 200711130000 & 200711160200 & 21.80 & 89.52 & $31 \mathrm{w}$ & $11 \mathrm{D}$ \\
72 & & 200711140000 & 200711161900 & 21.60 & 87.60 & $244 \mathrm{w}$ & $27 \mathrm{D}$ \\
48 & & 200711150000 & 200711152215 & 21.75 & 89.60 & $22 \mathrm{w}$ & $6.25 \mathrm{D}$ \\
24 & & 200711151200 & 200711151545 & 21.80 & 90.25 & $50 \mathrm{e}$ & $0.25 \mathrm{E}$ \\
\hline
\end{tabular}

$\mathrm{D}$ indicates forecast landfall time is delayed compared to actual time, $\mathrm{W}$ indicates west of the actual landfall position and $\mathrm{E}$ indicates forecast landfall time is earlier to actual landfall time. 
The landfall times and positions are tabulated in Table 6a. The error of landfall and time are also summaries in Table 6b. Mean position errors for 24, 48, 72 and $96 \mathrm{~h}$ are 117, 152, 89 and $69 \mathrm{~km}$ respectively and respective mean time errors are 8, 30, 8 and $1 \mathrm{~h}$.

Table 6b. Mean landfall position and time errors of selected tropical cyclone.

\begin{tabular}{|c|c|c|}
\hline Forcast Hours & $\begin{array}{l}\text { Mean landfall Position Error } \\
(\mathrm{km})\end{array}$ & $\begin{array}{llll}\begin{array}{l}\text { Mean landfall Time } \\
\text { (hrs) }\end{array} & \text { Error } \\
\end{array}$ \\
\hline $96 \mathrm{hrs}$ & 117 & 8 \\
\hline $72 \mathrm{hrs}$ & 152 & 30 \\
\hline $48 \mathrm{hrs}$ & 89 & 8 \\
\hline $24 \mathrm{hrs}$ & 69 & 1 \\
\hline
\end{tabular}

\section{Conclusion}

TC Sidr have been selected to simulate the structure, intensity, MSLP, wind (vector, radial, tangential, vertical wind), voticity, temperature anomaly and track by both of the models. Simulated parameters are compared with the data obtained from JTWC.

- $\quad$ Both the models are able to simulate some salient features of TC such as pressure distribution, vertical motion around the centre, vertical and horizontal distribution of wind, vorticity and temperature anomaly. Some of them are very close to the observations.

- Both of the models fail to simulate the SLP. Simulated SLP is higher than that of observed SLP. Spatial and temporal variation of minimum SLP obtained. But in all cases sharp pressure gradient in the vicinity of the centre of the TC are observed by the simulated pressure field at surface level.

- Asymmetric patterns of surface wind distribution with well organized banded structure having the maximum at about 40 to $240 \mathrm{~km}$ far from the centre and relatively weak winds at the centre are well simulated. Well organized circulation patterns are simulated at $850 \mathrm{hPa}$ level confirming that maximum winds are confined to the right of the track of the TC movement. Anticyclonic circulation patterns at $200 \mathrm{hPa}$ level or lower are visible in most of the cases. Model simulated MWS is nearly equal to the observed value.

- $\quad$ MM5 model predicts intensity better than WRF model.

- The model has successfully simulated the strong relative vorticity at lower level spreading over the strong convective region of each cyclone. For the very strong systems the positive vorticity is found to extend up to $100 \mathrm{hPa}$ level. Simulated low level vorticity fields at $850 \mathrm{hPa}$ level demonstrate the size of the system with strong convective regions of each cyclone, which are in agreements with the observations.

- The warm core characteristics with maximum temperature anomaly of $8-14{ }^{\circ} \mathrm{C}$ simulated in the middle and upper troposphere successfully by the models. This 
warm core has the vertical extends from the lower level to tropopause for strong system.

- With regard to track predictions of selected TC, models are run for 24, 48, 72 and $48 \mathrm{~h}$ forecast. Simulated track for 24 and $96 \mathrm{~h}$ forecast are the best among other forecasts for MM5 and WRF models respectively. Performance of WRF model for track prediction is better than MM5 model.

Considering the above, it can be mentioned that both the models simulate the cyclonic feature well. MM5 model has better forecast skill in terms of intensity prediction but WRF model has better forecast skill in terms of track prediction of the cyclonic storm. So, both of the models may be used as operational model by using the suitable microphysics and cumulus parameterization schemes.

\section{Acknowledgment}

The authors gratefully acknowledge the NCEP/NCAR for their reanalysis data sets used for the present study.

\section{References}

1. D. L. Zhang and X. Wang, Adv. Atmos. Sci. 20, 711 (2003). http://dx.doi.org/10.1007/BF02915397

2. U. C. Mohanty, M. Mandal, and S. Raman, Natural Hazards 31(2), 373 (2003). http://dx.doi.org/10.1023/B:NHAZ.0000023358.38536.5d

3. D. R. Pattanaik and Y. V. Rama Rao, J. Earth Syst. Sci. 118(4), 309 (2009). http://dx.doi.org/10.1007/s12040-009-0031-8

4. Y. V. R. Rao, H. R. Hatwar, K. S. Ahmed, and Y. Sudhakar, Pure appl. geophys. 164, 1593 (2007). http://dx.doi.org/10.1007/s00024-007-0244-1

5. P. J. Sousounis, T. A. Hutchinson, and S. F. Marshall - Preprints $20^{\text {th }}$ Conference on Weather Analysis and Forecasting (Seattle, Amer. Meteor. Soc., 2004).

6. W. Y. Y. Cheng and W. J. Steenburgh, Weather Forecasting 20, 812 (2005). http://dx.doi.org/10.1175/WAF885.1

7. K. P. Patra, M. S. Santhanam, K. V. J. Potty, M. Tewari, and P. L. S. Rao, Curr. Sci. 79(1), 70 (2000).

8. S. Pattanayak and U. C. Mohanty, Curr. Sci. 95, 923 (2008).

9. K. M. Z. Rayhun, D. A. Quadir, M. A. M. Chowdury, M. N. Ahsan, and M. S. Haque, J. Bangl. Acad. Sci. 39( 2), 157 ( 2015).

10. M. Mandal, U. C. Mohanty, and S. Raman, Natural Hazards 31, 391 (2004). http://dx.doi.org/10.1023/B:NHAZ.0000023359.24526.24

11. Y. Noh, W. G. Cheon, and S. Y. Hongs, Boundary -Layer Meteor. 107, 401 (2003). http://dx.doi.org/10.1023/A:1022146015946

12. P. Goswami, A. Mandal, H. C. Upadhyaya, and F. Hourdin, Mausam 57(1), 111 (2006).

13. D. V. B. Rao and D. H. Prasad, Mausam 57(1), 61 (2006). 